\title{
Determinant Factors of Health Financing Among Public and Private Sector in Malaysia
}

\author{
Zariyawati M. A. ${ }^{1}$, Hirnissa, M. T. ${ }^{2}$, Nurul-Farhanim, M. S. ${ }^{1}$, \& Soh, W. N. ${ }^{1}$ \\ ${ }^{1}$ School of Business and Economics, Universiti Putra Malaysia, Selangor, Malaysia. \\ ${ }^{2}$ Kolej Universiti Poly-Tech MARA, Kuala Lumpur, Malaysia \\ Correspondence: Zariyawati M.A., School of Business and Economics, Universiti Putra Malaysia, Selangor, \\ Malaysia.
}

Received: September 20, 2021

Accepted: November 3, 2021

Online Published: November 17, 2021

doi:10.5539/ibr.v14n12p113

URL: https://doi.org/10.5539/ibr.v14n12p113

\begin{abstract}
Health is a necessity for human well-being and productive. Hence, access to healthcare when needed is considered by many to be a basic human right. Therefore, it is important to invest in health financing to ensure access to healthcare for future needs, such as medical expenses. The current study aims to investigate the factors that influence employee spending on health financing in the public and private sectors in Malaysia. Further, we also examine whether the intention to spend on health financing differs between public and private sector employees. Multiple regression analysis and an independent-samples T-test were applied using SPSS to achieve this objective. Findings of this study reveal that employer and social influence factors influence the intention to spend on health financing in both sectors. Meanwhile, job factors only influence employees in the public sector to spend on health financing. We also found that the intention to spend on health financing differs between public and private sector employees.
\end{abstract}

Keywords: health financing, public sector, private sector, Malaysia

\section{Introduction}

Health can be defined as physical, mental, and social wellbeing and as a resource for living a full life. It refers not only to the absence of disease but also the ability to recover from illness and other problems. Factors for good health include genetics, the environment, relationships, and education. Good health is a sign that one can learn, work, and achieve full potential and enjoy one's daily life. Health is a fundamental necessity for human well-being, as good health leads to increased levels of productivity. Therefore, health is vital for everyone in life regardless of their career, profession and wealth.

Even though people are aware that health is important, many people's concern about health financing remains minimal. However, health financing plays an important role in ensuring financial protection for maintaining good physical health. Moreover, health financing refers to the function of a health system concerned with the mobilization, accumulation and allocation of money to cover the health needs of the people, individually and collectively, in the health system. The purpose of health financing is to make funding available, as well as to establish the right financial incentives for providers, to ensure that all individuals have access to effective public health and personal healthcare (WHO, 2000).

Malaysia's government spending on health expenditures increased from $7.3 \%$ in 2011 to $9.9 \%$ in 2021 . The national budget reveals that the government is concerned with allocating resources to healthcare. The year-to-year increase shows that the government is committed in giving better healthcare services to the Malaysian people. The health expenditures not only cover health financing for the cost of facilities such as hospitals, medical treatment, and doctors but also all health financing regarding healthcare, such as improvement of the services, providing initiatives in healthcare, and other important factors. Essentially, the increase in health financing is an attempt to improve health financing issues in Malaysia such as mobilization of funds, distribution of financial risks, allocation and utilization of services, and payment incentives (Phua, 2017). This shows that health financing is a crucial aspect in assessing government expenditure, as it provides the resources and economic incentives for the operation of health systems and is a key determinant of health system performance in terms of equity, efficiency, and health outcomes. 
Malaysia's government has devoted a large budgetary allocation to the health sector. However, the huge budget for health financing is not reflected in healthcare spending among the people (Khor, 2019). Rather, the interest in health financing among the Malaysian people remains minimal, despite the improved health services that the government provides. Nevertheless, financing for health is rising rapidly in both the public and private sectors. The provision of health financing by these two emloyees' sector has been widely debated among people as it has an extensive difference in the healthcare system, mainly in financing the balance between public and private sectors (Mills, 2020).

The public sector refers to government employees, while the private sector refers to non-government employees. In Malaysia, the majority of workers (52.5\%) are government employees, while the rest work in the private sector. Employees in the public sector are provided with subsidies for health financing, such as for hospital costs, medical costs, dental costs, health check-ups, and many other expenses. On the other hand, employees in the private sector are also provided with health financing by their companies, such as through company insurance and other healthcare services (Safurah et al., 2013).

Further, the spending on healthcare by public and private sector employees differs due to differences in the source and system. For example, several subsidies are given to public sector employees for receiving treatment from government hospitals. As a result, the costs of health financing are lower for these employees than for private sector employees. This is because Malaysia's government often make an effort to reduce out-of-pocket payments by subsidizing or providing free health services for the Malaysian people. This situation can be expected to influence public sector employees' unwillingness to spend money on healthcare and consequently to be less concerned with health financing. However, these subsidies do not apply to non-public-sectors employees when they come to government hospitals for treatment. Therefore, the private sector employees need to spend more on financing for their health care or medical costs, particularly when they do not receive sufficient medical benefits from their employers. Nonetheless, some of the private sector employees are not aware of the importance of health financing. In some cases, this is because they are insured or provided medical benefits by a private employer.

Despite having initiatives to cater the medical or health care by the employer in public and private sectors, some employees in both sectors are willing to invest in health financing matters. Some such employees spend part of their income on health insurance and other healthcare alternatives, include primary care membership plans, medical cost-sharing programs, health savings accounts (HSAs), and medical services discount cards. For example, some public sector employees who want cheaper service or treatment from private hospitals will opt to subscribe to health insurance. In addition, employees may be willing to invest and spend on health financing because they can get cheaper and better service in private hospitals without the need for a long wait before receiving treatment.

However, not all employees in the public and private sectors invest in health financing, either because of a lack of awareness or a lack of concern about their health. Income limitations and the need to spend their income on more immediate priorities such as food might make them unable to invest in health financing (Witter et. al., 2017). Hence, there are several factors that influence employees in the public and private sectors to invest in health financing. A study on the factors of health financing focusing on these two groups would offer insight into how people spend on healthcare. Henceforth, the purpose of this study is to investigate the determinant factors of health financing among public and private sector employees in Malaysia. Perhaps understanding the determinant factors of health financing among Malaysian employees could offer guidelines to improve the framework of the healthcare system and services within Malaysia. The current study also can increase the awareness of the importance of investing in health financing for health care.

\section{Literature Review}

\subsection{Health Financing}

According to Behera and Dash (2019), there is a difference in health financing between low- and middle-income countries. Specifically, low-income countries allocate far fewer financial resources to health sector development, resulting in higher out-of-pocket spending on health and poor health services. Moreover, the budget allocation for health financing is based on an economy's macro-fiscal policies, such as sustainable economic growth and improved revenue mobilization. Therefore, there is a difference in health financing according to the growth in the country as well as the income. According to World Health Organization, (WHO, 2011), income is the main factor for explaining differences across countries in the level and growth of total health care expenditures.

A study done by Topp et al. (2013) stated that government plays an important role in providing health services to people. They highlight that policy and administrative reform are needed to develop strong domestic health 
financing structures and allow effective health governance and planning. This means that government could be a key factor affecting health financing among people. In this study, government serves as a provider for the public sector, whereas the employer is the provider in the private sector.

A recent study by Krishnaswamy and Azeema (2017) found is significant relationship between employer factors and intention to purchase insurance. Specifically, company offerings and behavioural responses are is important in determining the factors of health financing with regard to the difference in health financing between the public and private sector. There also exists a social influence factor whereby people are influenced to spend on health financing when they have family and friends support. Sathyapriya (2018) reveals that family and friends are important sources of information and play a vital role in influencing people to spend on health care.

\subsection{Health Financing in Public and Private Sector in Malaysia}

Malaysian healthcare financing had been well administered by the government for the public sector and by the people themselves for the private sector. The government has financed the provision of medical and public health services through the consolidated revenue fund (CRAW) under the Ministry of Finance. The source of funding for CRAW comes from various taxes and revenues as well as income earned by government-corporatized enterprises, while the source of funds for private medical service providers is out-of-pocket expenses paid by the consumers buying medical services.

In public health financing, the system of financing is more beneficial to public sector employees. This is because they are only charged minimal rates, far below the prescribed Fee Schedule rates. The special rates are based on employer-employee collective agreements (General Order/Service circulars), which entitle them to obtain services at government hospitals and clinics, including corporatized institutions such as the UM Teaching Hospital and the IJN. The public health sector is well planned and well controlled through medium- and long-term planning and financing, resulting in a well-structured and mature system from the Central to the State, District, Mukim and Village levels, as well as between the urban and rural sector. The strengths of the public health sector are affordability to all, the policy of non-refusal to provide treatment, and comprehensive services through adequate facilities funded through the consolidated revenue fund (CRAW) with no additional cost to taxpayers (Malaysia Healthcare Travel Council (MHTC), 2020).

Meanwhile, in private health financing, private sector employees and self-employed workers pay according to the Fee Schedule. In the private sector, separate fees for service and fee schedules are in place with the approval of the Malaysian Medical Association (MMA). Overall, the private health sector caters well for affordable consumers. The strengths of the private health sector are facilities and services well spread, choices available based on affordability, minimal waiting lists, and specialist services available even without referral notes. Financing sources for private health financing include the insurance sector, including third-party payers, and other private hospitals. Moreover, the Employees Provident Fund (EPF) also serves as a third-party payer covering partial payment for catastrophic illnesses, which is limited to $10 \%$ of the member's savings (Kananatu, 2002). The Social Security Organisation (SOCSO) covers only employment-related illnesses and accidents or trauma. Both EPF and SOCSO cease their assistance when a member has retired, and this applies to both sectors, public and private. The biggest difference is that the government employees and their dependents enjoy the eligible classes of services even after their retirement, while EPF and SOCSO do not finance medical assistance for private sector employees after retirement.

\subsection{Factors Affecting Health Financing}

Malaysia has a dual-tier healthcare system, including a government-led and -funded public sector and a flourishing private sector, producing a dichotomous but synergistic model of public-private services (Yorulmaz, 2019). The government of Malaysia, for example, has introduced different forms of health insurance over the past 10 years, and Malaysia is currently designing a universal National Health Insurance (NHI) system to be funded largely by tax revenue. However, countries still face challenges in achieving equitable health care access and adequate financial risk protection, especially for vulnerable groups (Yip, 2019). Despite a slow growth rate in recent years, national healthcare spending will still increase to approximately $22 \%$ of the gross domestic product by 2038 under current law (WHO, 2012). There are certain factors that influence people in different sectors to spend on health care, as each sector provides different alternatives for health care financing.

\subsubsection{Job Factors}

Job factors are among the determinant factors of health financing. The main factor that influences health care financing and the distribution of health care benefits is affordability (Hirnissa et. al., 2018), which is closely related to the income gained by employees. In Malaysia, employees in the public sector will be most likely to 
have lower income compared to employees in the private sector (The 2011 Annual Survey of Hours and Earnings, 2011), and this can influence decisions related to spending. Additionally, the job characteristics in the public and private sector are obviously different. Work in the public sector provides advantages including job stability and the various high-quality benefits packages available. These include excellent retirement benefits and favourable insurance policies (Woodruff, 2014). Meanwhile, employment within the public sector makes it relatively easy to move from one public sector position to another whilst still retaining the same benefits, holiday entitlements, and sick pay as in the previous role. Hence, it is expected that different behaviour will be observed in health financing investment between public and private sector employees.

\subsubsection{Employer Factors}

In this study, the company or the employer plays the role of provider. The company offering refers to health care service received by employees in the private sector, who are provided by their employer with health care services such as health insurance and other health alternatives (Chua and Cheah, 2012). Even though employees in the private sector may not receive subsidized payments and services from the government, they are provided with company health insurance to cover their health care financing. Meanwhile, in the public sector, health care financing is mostly handled by the government. Public sector employees and their families enjoy free access to medical services provided by the public sector (MyGovernment, 2021). In contrast, in the private sector, the government may not cover health financing. However, some companies offer alternatives such as health care insurance for employees. Therefore, their employees' health care will be addressed. This shows that employer factors will affect health financing between employees in the public and private sector.

Moreover, behavioural response could be a factor that differentiates the determinant of health financing between employees in the public and private sector. For example, private sector employees' compulsory retirement income is solely from the Employees Provident Fund (EPF) savings that they accumulate during their working years. On the other hand, public sector employees are provided with retirement income from pension schemes. The retirement income can be used to bear the living costs during the retirement period, including medical costs and health care expenditures. Both public and private retirement plans contribute to the behaviour of the employees spending on health financing. The retirement savings is expected to be exhausted within 3 years upon reaching retirement age (Principal, 2021)). Previous studies also reported that retirees with EPF face a higher risk of having a lower replacement rate during retirement years compared to retirees with a pension scheme (Vaghefi et. al., 2017). Hence, employees should consider health financing if they realize the risk of having lower retirement savings.

\subsubsection{Social Influence Factors}

The decisions on spending for health financing are often more influenced by friends and family than they are by evidence-based medicine (Hajjaj et. al., 2010). This is because people are influenced by the good experiences share with them by close others, which influence their motivation to spend on health financing. Sathyapriya (2018) reveals that family and friends are seen as important sources of information and play a vital role in influencing people to spend for their health care. In conclusion, people will invest and spend on health financing after they know health financing investment is beneficial to theire life from close relative or people surrounding them.

\subsection{Theory Review}

Two theories are reviewed below to further explore the determinant factors of health financing among employees in the public and private sector.

\subsubsection{Rational Choice Theory}

It can be argued that all action is fundamentally 'rational' in character, as people consider the costs and benefits of any action before deciding what to do. This approach is known as rational choice theory, and its application to social interaction takes the form of exchange theory. According to rational choice theory, individuals make decisions when faced with choices, and individuals' decision-making process is determined by balancing the benefits and risks of the available options (Lumen Learning, 2021). Rational choice theory focuses on the rational behaviour of users rather than irrational and immediate reactions such as impulsive behaviour.

Rational behaviour occurs when a balance between perceived benefits and risks is needed, whereas impulsive behaviour is motivated by a stimulus such as individual trait tendencies and normative judgment (Ramanathan \& Menon, 2006). In the personalization context, the personalization paradox is often considered as a trade-off between benefit and risk factors. Hence, considering the cost-benefit trade-off, this paper focus on the rational choice perspective. Thus, we assume that employees of the public and private sector will consider the cost they 
will bear and benefits they will gain when making decisions to invest in health financing.

\subsubsection{Theory of Planned Behaviour}

The Theory of Planned Behaviour (TPB) illustrates that individual intention is governed by three constructs: attitudes, subjective norms, and perceived behavioural control (Ajzen, 1991). "Attitude" refers to the degree to which a person has a favourable or unfavourable evaluation or appraisal of a given behaviour (Ajzen, 1991). As suggested by Schultz (2000; 2001), people with high egoistic concerns will particularly consider the "perceived costs" and "perceived benefits" of environmental behaviour for themselves personally. When the "perceived benefits" exceed the "perceived costs", they will have an environmentally friendly intention, and vice versa. Meanwhile, "Subjective Norms" refer to the influence of external social factors on individuals' behaviour (Ajzen, 1991). Lastly, "Perceived Behavioural Control" refers to people's perception regarding the ease of performing the behaviour of interest (Ajzen, 1993). Although the predictive validity of TPB in a health-related study was limited (Orbell and Sheeran, 1998), the high suitability of adopting the TPB framework in a study of recycling intention is evident through the strong positive correlations between the above three constructs and recycling behaviour by path analysis (Strydom, 2018). The attitudes of public and private sector employees, their perceived benefits on health financing, and the influence from external social factors such as family influence employees to make decisions regarding health financing investment.

\subsection{Research Framework}

The model below shows the conceptual framework use in this research. The job factor, employer factor and social influence factor serve as independent variables, and intention to spend on health financing is the dependent variable. Further, the determinant factors on intention to spend on health financing is observed base on two working sector which is public and private sector.

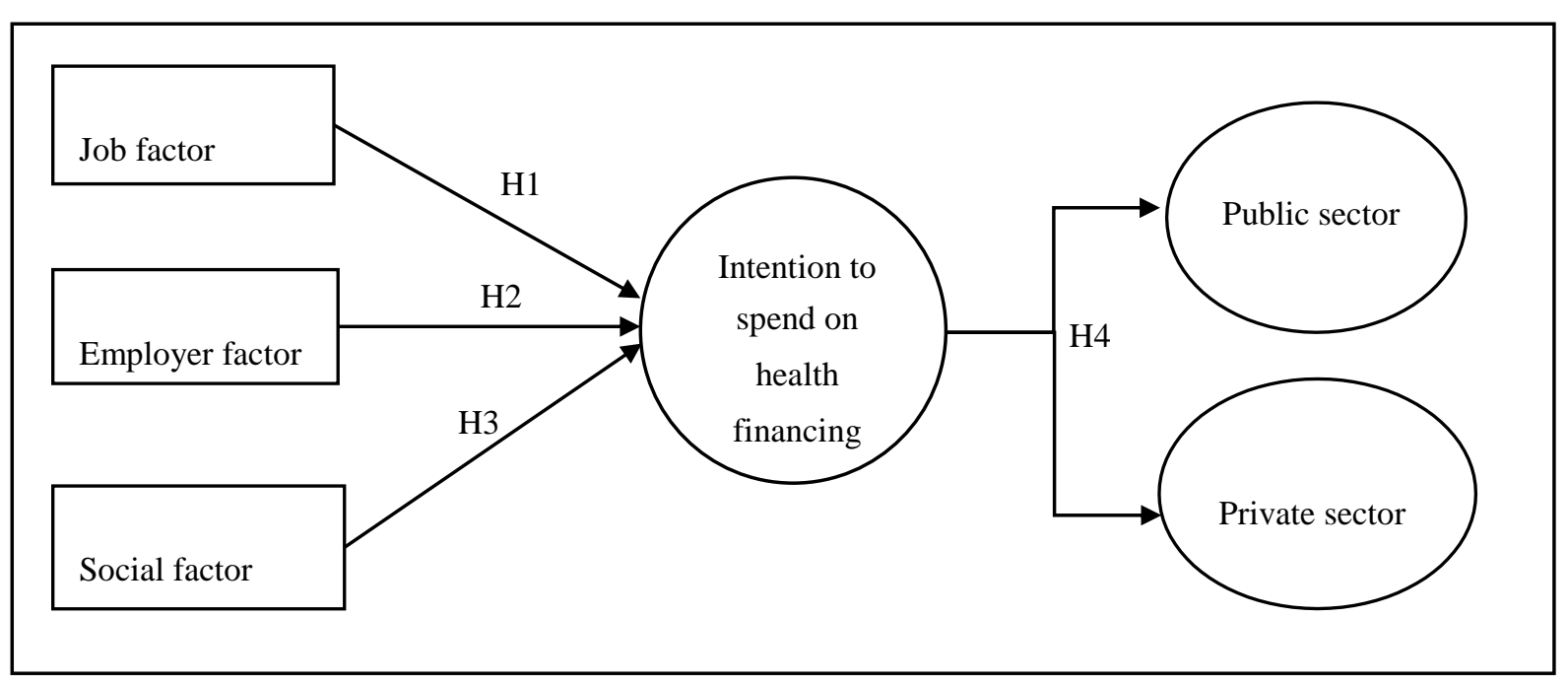

Figure 1. Conceptual Framework

\subsection{Hyphothesis Development}

This paper presents four hypotheses according to the proposed conceptual framework (see Figure 1), as follows:

H1: There is a significant relationship between the job factor and intention to spend on health financing among employees in the public and private sector.

H2: There is a significant relationship between the employer factor and intention to spend on health financing among employees in the public and private sector.

H3: There is a significant relationship between the social influence factor and intention to spend on health financing among employees in the public and private sector.

H4: There is a significant difference in the intention to spend on health financing among employees in the public and private sector.

\section{Method}

This section will describe the process of gathering, measuring, and examining data with regard to the research 
framework. The aspects to be discussed include the research design, target respondents, sampling technique, sample size, data collection method, and measurement instrument. The data will be examined via statistical tools such as reliability testing, descriptive statistics, independent sample t-testing and multiple regression analysis.

\subsection{Research Design}

A quantitative research design is used for this study to provide the largest amount of data to validate the relationship in the proposed framework (Khalid \& Kumar, 2012). In this study, quantitative research is useful to develop to explain the problem situation opposing the research and augment the understanding of the data.

\subsection{Target Respondent}

The target population for this study was employees in Malaysia. Target respondents include employees in the public sector and private sector.

\subsection{Sampling Technique}

Non-probability sampling was used because the sampling frame (names of employees) was not available. Non-probability sampling can be divided into four types, namely, quota sampling, purposive sampling (judgmental sampling), volunteer sampling (snowball sampling and self-selection sampling) and haphazard sampling (convenience sampling). In this study, quota sampling and judgmental sampling were adopted in order to select from a more representative sample so as to produce a more accurate result.

\subsubsection{Sample Size}

A sample size of 400 was chosen for this study. It is supposed that a sample size above 384 is large enough to impact the quality of the data and is normally capable of increasing the precision of the data when valuating unknown parameters during the analysis (Hair et. al., 2010). This study attempts to obtain a ratio of 50:50 for employees in both the public sector and private sector. However, due to the pandemic situation, we only managed to obtain 245 responses from private sector employees and 155 responses from public sector employees.

\subsubsection{Data Collection}

In this study, primary data collection was done through the survey method, wherein a set of questionnaires was prepared for distribution. The survey strategy was employed due to the nature of the research as well as the limited time and funding allocated for the study. The survey method is the most widely used strategy in the business and management research (Lumen Learning, 2021). The data collection was conducted for two months, from 1st February 2021 to 1st June 2021.

\subsubsection{Measurement}

The questionnaire consisted of classification questions to address sociological demographic variables including age, gender, ethnicity, and education level. The survey questions were closed-ended with a fixed set of choices. Variables such as age, education level and income level were measured using ordinal scales. Meanwhile, all the interval scales were taken from prior published scales that have shown high validity and reliability in past research. Five-point Likert scales ranging from " $1=$ Strongly Disagree" to " $5=$ Strongly Agree" were used to measure the responses. This part of the questionaire contained questions that measure the intention to spend on health financing among Malaysian employees and questions related to the determinant factors related to health financing among employees in the public and private sector. Intention to spend on health financing is a dependent variable. Meanwhile, job factor, employer factor and social influence factor are the independent variables of this study. The employer factor variable addresses what companies can provide to affect the health financing of their employees (Pei et. al., 2017). Employer-provided health insurance could have an important effect on health financing among employees (Gruber \& Poterba, 1996). Employees' decisions are often influenced more by anecdotes from friends and family than they are by evidence-based medicine. (Fagerlin et al., 2005).

\subsection{Data Analysis}

This study used the quantitative data analysis method to analyse the data to testify the hypotheses. Several statistical techniques were used to analyse the data collected such as validity and reliability testing, descriptive statistics, frequency testing, and the multiple regression-stepwise method. The Statistical Package for the Social Sciences (SPSS) software was used to analyse the data that were collected. 


\section{Result and Discussion}

\subsection{Reliability Analysis}

A reliability test was performed to measure the internal consistency of constructs used in this study. Nunnally (1978) asserted that a construct should have at least a minimum Cronbach's alpha of 0.7. Thus, any construct with a Cronbach's alpha of 0.7 or above is adequate for use in subsequent analysis. As can be seen from Table 1, all variables' reliabilities were higher than 0.70 . This shows that all the variables were reliable to use for further analysis (Nunnally, 1978).

Table 1. Reliability Score

\begin{tabular}{lccc}
\hline Variable & Items & Item deleted & Cronbach's alpha \\
\hline Job factor & 8 & - & 0.738 \\
Employer factor & 7 & 1 & 0.789 \\
Social factor & 4 & - & 0.836 \\
Intention & 5 & - & 0.826 \\
\hline
\end{tabular}

\subsection{Descriptive Analysis}

As shown in Table 2 below, descriptive analysis was used to examine the means and standard deviations for each variable. Since this study purpose is to observe the determinant factors of health financing among respondents in the public and private sector, the descriptive analysis is split into two groups as shown in Table 2.

Table 2. Descriptive Analysis

\begin{tabular}{llccccc}
\hline Working sector & & N & Minimum & Maximum & Mean & Std. Deviation \\
\hline Public sector & Job Factor & 155 & 1.63 & 5 & 3.5879 & 0.5840 \\
& Employer Factor & 155 & 1.00 & 5 & 3.7373 & 0.8147 \\
& Social Factor & 155 & 1.25 & 5 & 3.8226 & 0.7489 \\
& Intention & 155 & 2.80 & 5 & 4.2619 & 0.6408 \\
& Valid N (listwise) & 155 & & & & \\
Private sector & & & & & \\
& Job Factor & 245 & 1.75 & 5 & 3.6536 & 0.6561 \\
& Employer Factor & 245 & 1.71 & 5 & 3.6595 & 0.7249 \\
& Social Factor & 245 & 1.00 & 5 & 3.00 & 0.8935 \\
& Intention & 245 & 2.20 & 5 & 4.0735 & 0.6889 \\
& Valid N (listwise) & 245 & & & & \\
\hline
\end{tabular}

\subsection{Normality Test}

Normality test analysis is conducted to analyse whether the data is normally distributed. The values of skewness and kurtosis are observed in this study to identify the distribution of overall data. As shown in Table 3, the values of skewness and kurtosis for each variable in both groups is in the range of -1 and +1 , indicating that the data are normally distributed.

Table 3. Normality Test

\begin{tabular}{llccc}
\hline & Working sector & N & Skewness & Kurtosis \\
\hline Public sector & Job Factor & 155 & -0.238 & -0.045 \\
& Employer Factor & 155 & -0.364 & 0.046 \\
& Social Factor & 155 & -0.298 & -0.040 \\
& Intention & 155 & -0.457 & -0.829 \\
& Valid N (listwise) & 155 & & -0.479 \\
Private sector & Job Factor & 245 & 0.093 & -0.158 \\
& Employer Factor & 245 & -0.408 & -0.197 \\
& Social Factor & 245 & -0.379 & -0.805 \\
& Intention & 245 & -0.249 & \\
\hline
\end{tabular}




\subsection{Multiple Regression Analysis: Findings for $\mathrm{H1}, \mathrm{H2}$, and $\mathrm{H3}$}

Multiple regression analysis was used in this study to measure the relationship between the dependent variable and three independent variables which relate to $\mathrm{H} 1, \mathrm{H} 2$ and $\mathrm{H} 3$. Table 4 below shows the multiple regression summary for the responses of employees in the public and private sectors. F-tests are often used when comparing statistical models that have been fitted to a data set, to identify the model that best fits the population from which the data were sampled. A high value of $\mathrm{F}$ means that the data are significant. Table 4 shows that the value of $\mathrm{F}$ for respondents in the public sector is 25.09 , while it is 81.12 in the private sector, which illustrates that the data in both groups are significant at the $5 \%$ level and considered to fit with the model.

Moreover, the $\mathrm{R}^{2}$ value shows that the public sector has a value of 0.332 , indicating that only $33.2 \%$ of the intention to purchase health care service is explained by the independent variables. Meanwhile, the higher $\mathrm{R}^{2}$ value in the private sector, 0.502 , indicates that that $50.2 \%$ of the intention to purchase health care services is explained by the independent variables. This reveals that the independent variables influence the dependent variable more among private sector employees than public sector employees.

The Durbin Watson values are 1.561 and 1.941 in the public and private sector, respectively; these both fall in the range between 1 and 3, meaning that the data have no autocorrelation issues and are free from independent errors. Moreover, collinearity statistics were also observed to ensure that each of the independent variables in the data are free from multicollinearity by looking at the Tolerance and VIF values. Data are considered free from multicollinearity issues when the value of Tolerance is greater than 0.1 and VIF is less than 3.0. It is obvious that all of the independent variables in both of the groups are free from multicollinearity issues, as they have Tolerance values greater than 0.1. Similarly, each of variables in both groups have VIF values less than 3.0, meaning that the data do not suffer from multicollinearity issues.

Table 4. Multiple Regression for Public and Private Sector

\begin{tabular}{|c|c|c|c|c|c|c|c|}
\hline \multirow[b]{2}{*}{ Variables } & & \multirow[b]{2}{*}{ Coefficient } & \multirow[b]{2}{*}{$\mathrm{t}$} & \multirow[b]{2}{*}{ Sig. } & \multirow[b]{2}{*}{ Model Statistics } & \multicolumn{2}{|c|}{ Collinearity Statistics } \\
\hline & & & & & & Tolerance & VIF \\
\hline \multirow{4}{*}{$\begin{array}{l}\text { Public } \\
\text { Sector }\end{array}$} & Constant & 1.638 & 5.337 & 0.000 & $\mathrm{R} 2=0.332$ & & \\
\hline & Job Factor & 0.282 & 3.102 & 0.002 & Durbin Watson $=1.561$ & 0.644 & 1.552 \\
\hline & Employer Factor & 0.195 & 3.227 & 0.002 & F-value $=25.009$ & 0.749 & 1.334 \\
\hline & $\begin{array}{l}\text { Social Influence } \\
\text { Factor }\end{array}$ & 0.231 & 3.720 & 0.000 & $($ sig. $=0.000)$ & 0.840 & 1.190 \\
\hline \multirow{4}{*}{$\begin{array}{l}\text { Private } \\
\text { Sector }\end{array}$} & Constant & 1.257 & 6.025 & 0.000 & $\mathrm{R} 2=0.502$ & & \\
\hline & Job Factor & 0.102 & 1.897 & 0.089 & Durbin Watson $=1.941$ & 0.789 & 1.267 \\
\hline & Employer Factor & 0.280 & 5.795 & 0.000 & F-value $=81.129$ & 0.799 & 1.251 \\
\hline & $\begin{array}{l}\text { Social Influence } \\
\text { Factor }\end{array}$ & 0.374 & 9.321 & 0.000 & $($ sig. $=0.000)$ & 0.763 & 1.311 \\
\hline
\end{tabular}

To identify the significance of each variable for the health financing intention, coefficients were observed. Table 4 shows that job factors $(0.282)$, employer factors $(0.195)$ and social influence factors $(0.231)$ have a positive relationship at the 5\% significance level with the intention to spend on health financing among employees in the public sector, as the p-values are less than 0.05 . The positive and significant relationship indicates that the decisions of employees in the public sector to spend on health financing are influenced by job, employer and social influence factors. However, only employer factors $(0.280)$ and social influence factors $(0.374)$ have a positive relationship at the 5\% significance level with the intention to spend on health financing among employees in the private sector. There is no significant relationship between job factors $(0.102)$ and the intention to spend on health financing among employees in the private sector. The results reveal that the decision of employee in private sector to spend on health financing is influence by the employer factor and social influence factor only. The multiple regression results support $\mathrm{H} 1, \mathrm{H} 2$ and $\mathrm{H} 3$ in the public sector, while only $\mathrm{H} 2$ and $\mathrm{H} 3$ are supported in the sample of private sector in this study.

The job factor significantly influences the intention to spend on health financing among employees in the public sector. However, it does not apply to the private sector employees. The result reveals that public sector employees have the intention to purchase health care services based on their income, characteristics, and environmental factors of their job. The higher the income the employees in the public sector receive, the more they will spend on health financing. Employees also have the intention to spend on health financing for health 
care products/services if they believe the environmental factor such as workplace and the job characteristics require them to spend more on medical expenses, such as those due to injuries. The result was consistent with Hirnissa et al. (2018), who found that affordability is the most common factor influencing health care financing and the distribution of health care benefits among people. This shows that increased income increases the demand for health care services and increases health spending among employees. On the other hand, the insignificant relationship between the job factor and intention to spend on health financing among employees in the private sector is in line with Marmot (2002), who suggests that it may not be income itself that matters for people's spending on health financing. Rather, they might spend on health financing because they need it, since employees in the private sector are provided with fewer health care services by their employer compared to employees in the public sector.

The employer factor significantly influenced the intention to spend on health financing among employees in both sectors. This is aligned with Chua and Cheah (2012), who suggests that company offers and benefits have contributed to the rise in health spending. Company offers as an indicator demonstrate that employees agree that the employer factor does influence the intention to purchase health care services among employees. Therefore, employees are aware the importance of health care because their companies have provided health care services to them. As a result, they intend to spend on health financing and to purchase or subscribe to more health care products or services.

The social influence factor was also found to influence the intention to spend on health financing by employees in the public and private sectors. This is in line with Hajjaj et. al. (2010), who proved the social factor captured the most significant value, as employees' decisions are often influenced more by friends and family than by evidence-based medicine. Moreover, purchases of insurance are influenced by word-of-mouth about the benefits. Employees in both sectors are aware of the the importance of health care and have the intention to spend on health financing when they know that people around them spend on health care products and share the benefits of doing so.

\subsection{Independent Sample t-Test: Results and Discussion for Hypothesis 4}

Hypothesis 4 (H4) examined whether the intention to spend on health financing is difference among employees in the public and private sector. Independent sample t-tests were conducted to test $\mathrm{H} 4$. As can be seen in Table 5, Levene's test for equality of variance is 0.42 , which is higher than the significant p-value of 0.05 . Hence, we cannot reject the null hypothesis of Levene's test, which mean that the assumption of equal variances is accepted. Therefore, the variances of respondents in the public sector and private sector are similar. This indicates that we need to refer to the t-value obtained from the first row of Table 5, which assumes equal variances, to check the findings for H4. The significance level for equal variances assumed exhibits the t-test was $0.006(\mathrm{p}<0.05)$, indicating that there are significant differences in the intention to spend on health financing between employees in the public sector and private sector. Thus, $\mathrm{H} 4$ is supported. This is consistent with the findings for $\mathrm{H} 1, \mathrm{H} 2$ and H3. All three factors (job, employer, and social influence) tested in multiple regression analysis significantly influence the intention of employees in the public sector to spend on health financing. However, only two factors (employer and social influence) significantly influence the intention of employees in the private sector to spend on health financing.

Table 5. Levene's Test for independent sample t-test

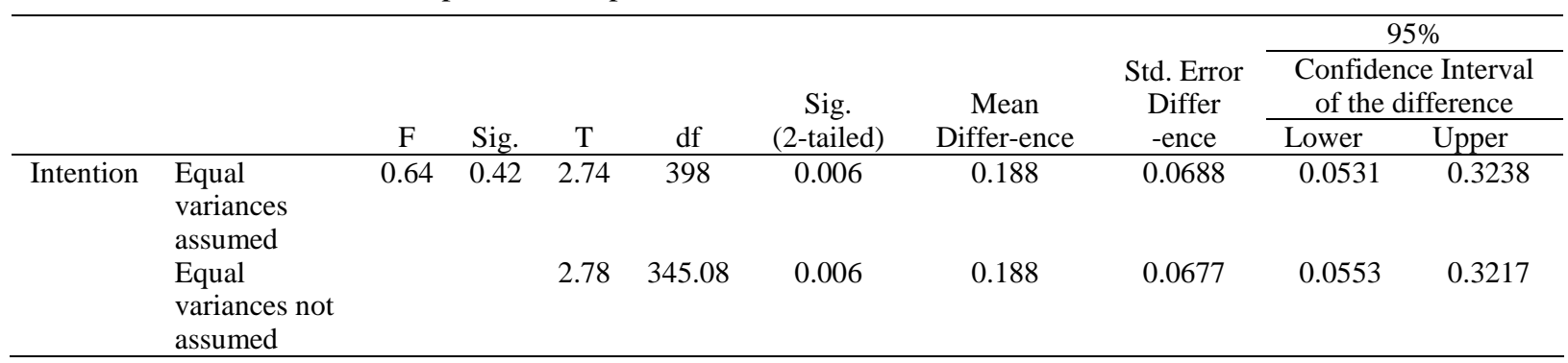

Referring to the earlier Table 2, the means of employees in the public sector and private sector are 4.26 and 4.07 , respectively. The higher mean of employees in the public sector reveals that they have the intention to spend more on health financing compared to the employees from the private sector. The intention to spend more on health financing by public sector employees is because they believe the medical benefit provided by the 
government has limitations and is not adequate to support the cost for certain medical issues. Further, the public sector employees are willing to spend on health financing rather than depend solely on the employer because they are looking for better medical treatment service and wider coverage. For example, then can enjoy better facilities with cheaper costs in non-government hospitals, as well as less waiting time to get treatment and additional coverage for family members. This is supported by the previous study done by Woodruff (2014), which suggest that the difference in average salary result in the different behaviorial intention between public sector and private sector employees with regard to health financing. According to the Bureau of Economic Analysis, employees in the public sector earn an average of 11.4 percent lower salary than private-sector workers of similar education and work experience. This is because in the public sector, employees are typically protected by law and thus are not subject to competitive incentives and pressures (Summers, 2010). Hence, the range of wages would be fixed for employees in the public sector. Conversely, in the private sector, wages and employment come with less stability. The private sector has fewer legal barriers to hiring and laying off employees, although they are subject to anti-discrimination rules, and they carry legal liability associated with human resources (Lazzari, 2019). The range of wages can thus be much higher or much lower than in the public sector. Therefore, the health financing spending between these two groups might have contradict which is proven by findings of the current study.

\section{Conclusion}

In this study, the determinant factors that influence the intention to spend on health financing among public and private sector employees in Malaysia were investigated. There are significant differences in the intention to spend on health financing between employees in these two working sectors. Specifically, job, employer, and social influence factors influence the intention of employees in the public sector to spend on health financing for health care products and services. However, the decision to spend on health financing among employees in the private sector is influenced only by the employer factor and social influence factor. The findings of this study may benefit government and other related stakeholders such as employers, hospitals, and health insurance companies in designing strategies to attract more people to spend on health financing. More people are spending on health security and to prevent them from facing financial problems in the future to pay for medical expenses. However, the use of convenience sampling and testing of the three determinant factors may be limitations of this study. Hence, additional determinant factors are recommended for future research to attain a more holistic understanding of factors influencing health financing among employees in Malaysia as a whole.

\section{Acknowledgments}

The authors would like to thank the Research Assistants, Safikah Najihah Binti Idris, in for helping us to complete this paper.

\section{References}

Ajzen, I. (1991). The theory of planned behavior. Organizational Behavior and Human Decision Processes, 50(2), 179-211. https://doi.org/10.1016/0749-5978(91)90020-T

Behera \& Dash. (2019). Global Health Research and Policy, 4(21). https://doi.org/10.1186/s41256-019-0112-4

Chua, H. T., \& Cheah, J. C. H. (2012, June). Financing universal coverage in Malaysia: a case study. In BMC public health (Vol. 12, No. 1, pp. 1-7). BioMed Central. https://doi.org/10.1186/1471-2458-12-S1-S7

Fagerlin, A., Wang, C., \& Ubel, P. A. (2005). Reducing the influence of anecdotal reasoning on people's health care decisions: is a picture worth a thousand statistics? Medical decision making, 25(4), 398-405. https://doi.org/10.1177/0272989X05278931

Gruber, J., \& Poterba, J. (1996). Fundamental tax reform and employer-provided health insurance. Economic Effects of Fundamental Tax Reform, 125-170. https://doi.org/10.3386/w5147

Hair, J. F., Black, W. C., Babin, B. J., \& Anderson, R. E. (2010). Multivariate data analysis. Englewood Cliffs, NJ: Prentice Hall.

Hajjaj, F., Salek, M., Basra, M., \& Finlay, A. (2010). Non-clinical influences on clinical decision-making: A major challenge to evidence-based practice. Journal of the Royal Society of Medicine, 103(5), 178-187. https://doi.org/10.1258/jrsm.2010.100104

Hirnissa, M. T., \& Zariyawati, M. A. (2018). An exploratory study on determinant of health financing by household in Malaysia. International Journal of Accounting, 3(16), 20-34.

Kananatu, K. (2002). Healthcare Financing in Malaysia. Asia Pacific Journal of Public Health, 14(1), 23-28. https://doi.org/10.1177/101053950201400106 
Khalid, K., \& Kumar, M. D. (2012). Get Along with Quantitative Research Process. International Journal of Research in Management, 2(2).

Khor, S. K. (2019). Budget 2020: More for healthcare with some missed opportunities. Retrieved from https://www.thestar.com.my/opinion/columnists/vital-signs/2019/10/23/budget-2020-more-for-healthcare-w ith-some-missed-opportunities

Krishnaswamy, J., \& Azeema, N. (2017). Factors influencing the purchase intention of health insurance policy-an empirical study in Malaysia. International Journal of Economic Research, 14(16).

Lazzari, Z. (2019). What Is the Meaning of Public Sector Employment vs. Private? CHRON. Retrieved from https://courses.lumenlearning.com/suny-hccc-research-methods/chapter/chapter-9-survey-research/

Marmot, M. (2002). The Influence Of Income On Health: Views Of An Epidemiologist. Health Affairs, 21(2), 31-46. https://doi.org/10.1377/hlthaff.21.2.31

MHTC. (2020). The healthcare system in Malaysia. Malaysia Healthcare Travel Council. Retrieved from https://www.mhtc.org.my/2020/02/02/the-healthcare-system-in-malaysia/

Mills, A. (2020). The health systems of low- and middle-income countries. Public Health. https://doi.org/10.1093/obo/9780199756797-0199.

MyGovernment. (2021). Mendapat Maklumat Bantuan \& Kemudahan bagi Pesara Kakitangan Awam. Unit Pemodenan Tadbiran Dan Perancangan Pengurusan Malaysia. Retrieved from https://www.malaysia.gov.my/portal/content/29512

Nunnally, J. (1978). Psychometric Theory. McGraw-Hill, New York.

Orbell, S., \& Sheeran, P. (1998). 'Inclined abstainers': A problem for predicting health-related behaviour. British Journal of Social Psychology, 37, 151-165. https://doi.org/10.1111/j.2044-8309.1998.tb01162.x

Pei, X., Luo, H., Lin, Z., Keating, N., \& Fast, J. (2017). The impact of eldercare on adult children's health and employment in transitional China. Journal of cross-cultural gerontology, 32(3), 357-372. https://doi.org/10.1007/s10823-017-9330-8

Phua, K. (2017). International encyclopedia of public health. Governance Issues in Health Financing, 330-341. https://doi.org/10.1016/B978-0-12-803678-5.00177-6

Principal. (2021). Why should you take your retirement savings off autopilot? Principal Alliance with CIMB. Retrieved from https://www.principal.com.my/en/why-you-should-take-your-retirement-savings-autopilot

Ramanathan, S., \& Menon, G. (2006). Time-Varying Effects of Chronic Hedonic Goals on Impulsive Behavior. SSRN Electronic Journal. https://doi.org/10.2139/ssrn.778944

Safurah, J., Kamaliah, M. N., Khairiyah, A. M., Nour Hanah, O., \& Healy, J. (2013). Malaysia health system review: Health systems in transition. WHO Regional Office for the Western Pacific.

Sathyapriya, S. (2018). A Study On Awareness and Accessibility of Rural Insurance Products Among Rural People.

Strydom, W. (2018). Applying the theory of planned behavior to recycling behavior in South Africa. Recycling, 3(3), 43. https://doi.org/10.3390/recycling3030043

Summers, A. B. (2010). How California's public pension system broke (and how to fix it). Reason.

Taherdoost, H. (2016). Sampling methods in research methodology; How to choose a sampling technique for research. SSRN Electronic Journal. https://doi.org/10.2139/ssrn.3205035

Topp, M. S, Candice, M., Homaie, R. E., Vahedi, S., Teimourizad, A., Esmaeilzadeh, F., ... Torabi Pour, A. (2013). Comparison of the effects of public and private health expenditures on the health status: a panel data analysis in eastern Mediterranean countries. International journal of health policy and management, 1(2), 163-167. https://doi.org/10.15171/ijhpm.2013.29

Vaghefi, N., Kari, F., \& Talib, M. A. (2017). Poverty and income replacement profile among EPF retiree in Malaysia. Social Indicators Research, 132(3), 1065-1078. https://doi.org/10.1007/s11205-016-1326-1

WHO. (2000). The World Health Report 2000. Health systems: Improving Performance. World Health Organization. https://www.who.int/whr/2000/en/whr00_en.pdf

WHO. (2011). World Health Statistics. World Health Organization. Retrieved from https://www.who.int/gho/publications/world_health_statistics/EN_WHS2011_Full.pdf 
Witter, S., Govender, V., Ravindran, T. S., \& Yates, R. (2017). Minding the gaps: Health financing, universal health coverage and gender. Health Policy and Planning, 32(suppl_5), v4-v12. https://doi.org/10.1093/heapol/czx063

Woodruff, J. (2020). The Differences Between Government Employment and Private Sectors. CHRON.

Yip, W. (2019). Healthcare system challenges in Asia. In Oxford Research Encyclopedia of Economics and Finance. https://doi.org/10.1093/acrefore/9780190625979.013.245

Yorulmaz, M., \& Mohamed, N. N. (2019). Malaysia health system review: overviews and opinions. In International Journal of Health Administration and Education Congress (Sanitas Magisterium) (Vol. 5, No. 1, pp. 45-57).

\section{Copyrights}

Copyright for this article is retained by the author(s), with first publication rights granted to the journal.

This is an open-access article distributed under the terms and conditions of the Creative Commons Attribution license (http://creativecommons.org/licenses/by/4.0/). 